\title{
Repeated modification of early limb morphogenesis programmes underlies the convergence of relative limb length in Anolis lizards
}

\author{
Thomas J. Sanger ${ }^{1,2, *}$, Liam J. Revel1 ${ }^{3}$, Jeremy J. Gibson-Brown ${ }^{4}$ \\ and Jonathan B. Losos ${ }^{1,2}$ \\ ${ }^{1}$ Department of Organismic and Evolutionary Biology, and ${ }^{2}$ Department of Herpetology, Museum of \\ Comparative Zoology, Harvard University, 26 Oxford Street, Cambridge, MA 02138, USA \\ ${ }^{3}$ Department of Biology, University of Massachusetts Boston, 100 Morrissey Boulevard, Boston, \\ MA 02125-3393, USA \\ ${ }^{4}$ Department of Biology, Central Michigan University, Brooks 138, Mount Pleasant, MI 48859, USA
}

\begin{abstract}
The independent evolution of similar morphologies has long been a subject of considerable interest to biologists. Does phenotypic convergence reflect the primacy of natural selection, or does development set the course of evolution by channelling variation in certain directions? Here, we examine the ontogenetic origins of relative limb length variation among Anolis lizard habitat specialists to address whether convergent phenotypes have arisen through convergent developmental trajectories. Despite the numerous developmental processes that could potentially contribute to variation in adult limb length, our analyses reveal that, in Anolis lizards, such variation is repeatedly the result of changes occurring very early in development, prior to formation of the cartilaginous long bone anlagen.
\end{abstract}

Keywords: evo-devo; parallel evolution; convergent evolution; allometry

\section{INTRODUCTION}

From some of the earliest evolutionary speculation to the present day, developmental drivers of evolution have been viewed as an alternative to adaptationist explanations for evolutionary patterns (e.g. [1-3]; reviewed in $[4,5]$ ). The basic argument has revolved around the issue of which is more important in determining evolutionary patterns: developmental factors that constrain the variation that is produced, or selective factors that determine how genetic variation is selected across generations (e.g. [6-9])?

A particular case of contention is that of convergent evolution. The independent evolution of similar phenotypes (morphologies) in similar environments has long been taken as evidence of the primacy of natural selection (reviewed in [8]). However, in recent years, workers have argued that convergence-and, in particular, what is sometimes called 'parallel evolution', in which convergent patterns are produced through similar developmental changes - is evident for the biasing role of development in shaping evolutionary patterns $[7,10-15]$. But these views are not necessarily mutually exclusive. On one hand, convergence per se does not necessarily imply the similar action of natural selection; only when convergence occurs in similar selective environments is adaptive evolution implied [8]. Even in such cases, however, the channelling effects of shared developmental programmes may still be important by limiting the universe of possible

* Author for correspondence (tsanger@oeb.harvard.edu).

Electronic supplementary material is available at http://dx.doi.org/ $10.1098 / \mathrm{rspb} .2011 .0840$ or via http://rspb.royalsocietypublishing.org. variation upon which selection can operate. In this view, a key question is whether convergent phenotypes are produced by convergent developmental changes.

For most of the 20th century, the fields of evolutionary biology and developmental biology progressed in parallel, acquiring independent research objectives and experimental techniques [5,16]. But renewed interest in the developmental mechanisms of morphological evolution in the late 1970s and 1980s-stimulated, in part, by the works of Gould [17] and the discovery of pan-metazoan Hox gene conservation [18] - galvanized the field of evolutionary developmental biology. Recently, much attention in evolutionary developmental biology has been given to uncovering the molecular bases of morphological evolution and whether changes in the action of the same genes underlie phenotypic convergence [19-22]. But phenotypic convergence can result from non-convergent genotypic evolution (reviewed in [23-25]). To fully understand the developmental bases of convergent phenotypes, it is therefore critical that detailed analyses of developmental mechanisms be placed within the appropriate phenotypic context.

Evolutionary developmental biology has predominantly focused on studying dramatic morphological changes where the scoring of discrete phenotypes rarely requires detailed measurement [26,27]. By contrast, much of the study of natural selection and evolutionary diversification focuses on traits that vary quantitatively rather than qualitatively, such as body size, limb length and head shape [28-30]. While many of these qualitative shifts in morphology have been linked to changes in early development $[19-21,31]$, variation in quantitative traits 
(a)

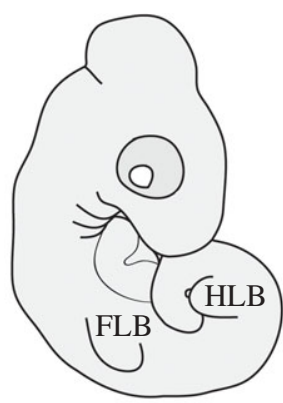

limb bud outgrowth and patterning

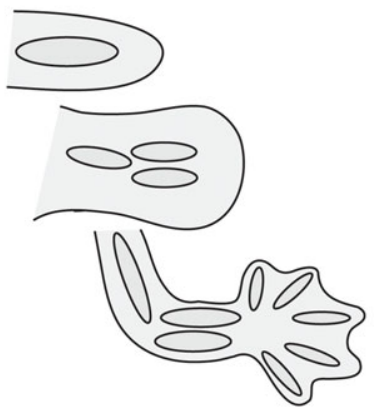

morphogenesis

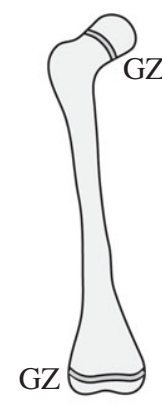

growth

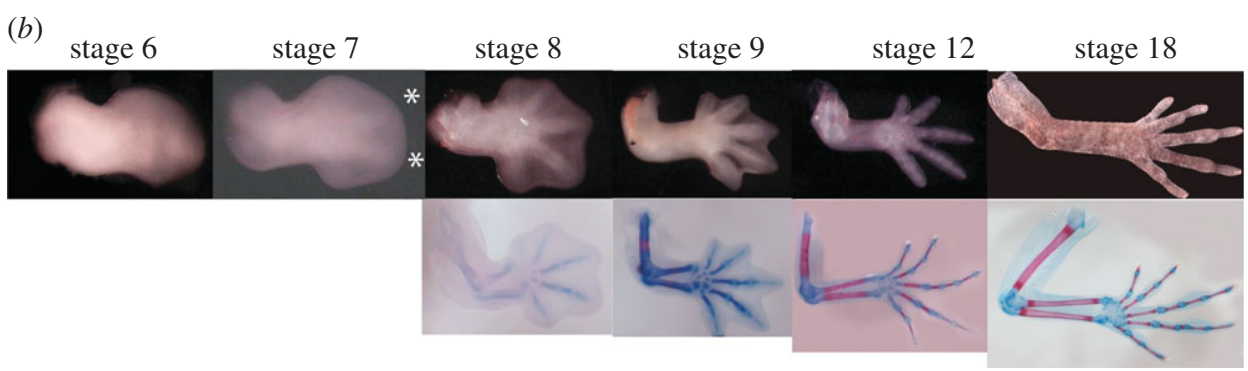

Figure 1. (a) Summary of limb and long bone development. Limb development proceeds through several stages: limb bud outgrowth and patterning, when the limb bud is only filled with undifferentiated mesenchyme; morphogenesis, where the cartilaginous anlagen of the limb bones form; and growth, mediated from epiphyseal growth zones. FLB, forelimb bub; HLB, hindlimb bud; and GZ, growth zone. (b) Limb development for Anolis sagrei. Asterisks denote visible condensations in the digital plate of stage 7 embryos. The earliest samples in our study were collected during stage 9 , the earliest time when cartilage stains with Alcian blue.

often has complex developmental origins: variation can arise through changes in morphogenesis, differential growth rates or both [32-37]. The most critical question to address first when studying the developmental bases of convergent quantitative phenotypes is whether the morphologies arise through convergent developmental trajectories representing the full developmental history of a structure [38].

Caribbean Anolis lizards provide an excellent and extensively studied group for investigating the repeated, independent evolution of similar morphologies (reviewed in [30]). Anoles have radiated, for the most part, independently on each island in the Greater Antilles (Cuba, Hispaniola, Jamaica and Puerto Rico), producing essentially the same set of habitat specialists-termed 'ecomorphs' - on each island. Of particular importance in this repeated ecomorphological specialization is variation in relative limb length (i.e. limb length controlled for body size), which is known to play a significant role in adaptation to different parts of the structural habitat (e.g. tree trunks, twigs and grass blades). Despite many years of ecological and evolutionary research on this genus, the developmental bases of limb length variation have not yet been examined. Just how many different ways has variation in relative limb length evolved in this genus? Discovering that species converge morphologically via similar developmental trajectories might suggest that anoles have inherited common patterns of variation from their ancestor, potentially biasing the response to selection. But finding that different lineages converge morphologically using different developmental mechanisms would indicate that natural selection was the primary factor determining evolutionary trajectories. The goal of this work was to test the hypothesis that species possessing similar limb morphologies have converged on these morphologies through similar alterations to their growth trajectories.

\section{METHODS}

\section{(a) Overview}

Predicting potential mechanisms of divergence first requires a general understanding of limb development (figure 1). During embryonic development, limb buds irrupt from the flank of the animal and are filled with an undifferentiated mesenchyme. During patterning, mesenchymal cells aggregate and differentiate to form a single cartilaginous anlagen, the precursor to the limb long bones. This cartilaginous rod then grows and bifurcates to form the limb skeleton. Ossification begins as a bony collar around each anlage, which expands towards the ends of the bone, establishing a growth zone. From this time on, proximodistal extension occurs solely at the growth zone, although the precise mechanism is unclear in reptiles (T. J. Sanger \& C. E. Farnum 2004, personal observation). Variation in adult long bone length can therefore either result from variation generated during limb bud patterning, influencing the initial dimensions of the anlagen, or through differential rates of long bone elongation via the action of growth plates at either end of the bone.

Interpreting evolutionary and developmental changes in relative size is best done in the context of allometry. Ontogenetic allometry, in particular, examines the relationship between local versus global rates of growth [39]. Several alternative allometric hypotheses could account for the patterns of limb length variation observed in adult Anolis lizards (figure 2). Variation in limb length may be due to localized 


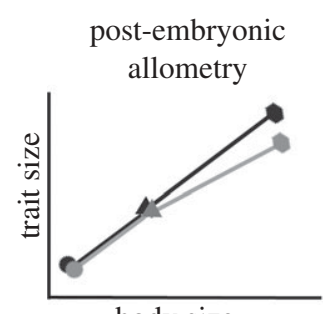

body size

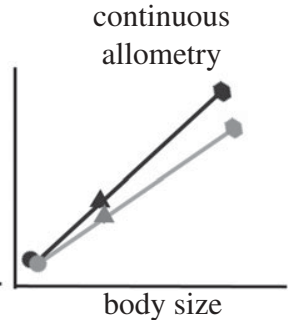

body size

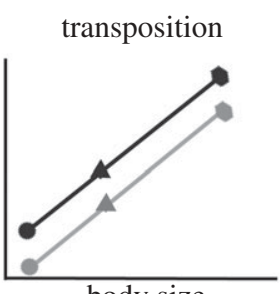

body size ontogenetic

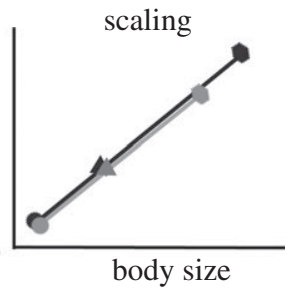

Figure 2. Suite of alternative allometric hypotheses contrasting hypothetical species pairs. During post-embryonic allometry, species share similar embryonic trajectories, but diverge in relative size after hatching. Continuous allometry refers to a pattern in which species appear similar following morphogenesis, but subsequently diverge. A transposition of the allometric regressions reflects that a change has occurred prior to the earliest developmental stages measured. During scaling, the absolute size of the trait changes, but in proportion to body size. Circles, morphogenesis; triangles, hatching; hexagons, adulthood.

changes in the rate of limb growth, either from the initial stages of morphogenesis (continuous allometry) or through stagespecific changes that occur later in ontogeny (post-embryonic allometry). These are both represented by a change in the slope of the allometric regression. Variation in adult morphology may also be the result of changes that occur during morphogenesis, represented by a transposition, or a shift in the intercept of the allometric regressions. Variation in adult morphology can also arise by scaling (extending or compressing) an allometric trajectory. However, in this case, we compare species that are roughly the same adult body size, indicating that this explanation cannot account for differences in relative limb length in these species. Long bone development is a complex process and, as a result, limb length variation can arise through many processes, whether by changing the patterning of the early limb bud or through time-specific changes in growth rate (e.g. [34,35,37,40-44]).

Detailed description of our methodology is included in the electronic supplementary material, appendix S1. Here, we briefly describe our study species, specimen preparation and statistical analyses.

\section{(b) Study species and specimen preparation}

We collected growth series for eight Caribbean Anolis species representing one trunk-ground and one trunk-crown ecomorph from each island in the Greater Antilles (figure 3). Trunk-ground species have relatively longer limbs than trunk-crown species [30]. Limb patterning occurs early in development, and establishes the initial size and shape of the skeletal anlagen (figure 1). To extend juvenile patterns of allometric long bone growth closer to the period of morphogenesis, we also collected embryological series for four species-the trunk-crown and trunk-ground specialists from Cuba and Jamaica. These species were chosen because of their relative ease of care in captivity and the rate at which they lay eggs. Detailed methods of embryo collection have been described elsewhere $[45,46]$.

As is common in herpetological studies in general, and previous studies of anoles in particular (e.g. $[47,48]$ ), we used snout-to-vent length (SVL) as a standard measure of body size. For embryological comparisons, we collected one to three individuals per stage for each of the four species examined, from the early stages of digital webbing reduction (stage 9/10) through hatching (stage 19 [45]). Combined with the post-hatching series, this represents nearly the entire period of long bone skeletal development and growth (figure 1).

We prepared post-hatching skeletons with standard clearing and staining protocols [49-51]. Scaled digital photographs of

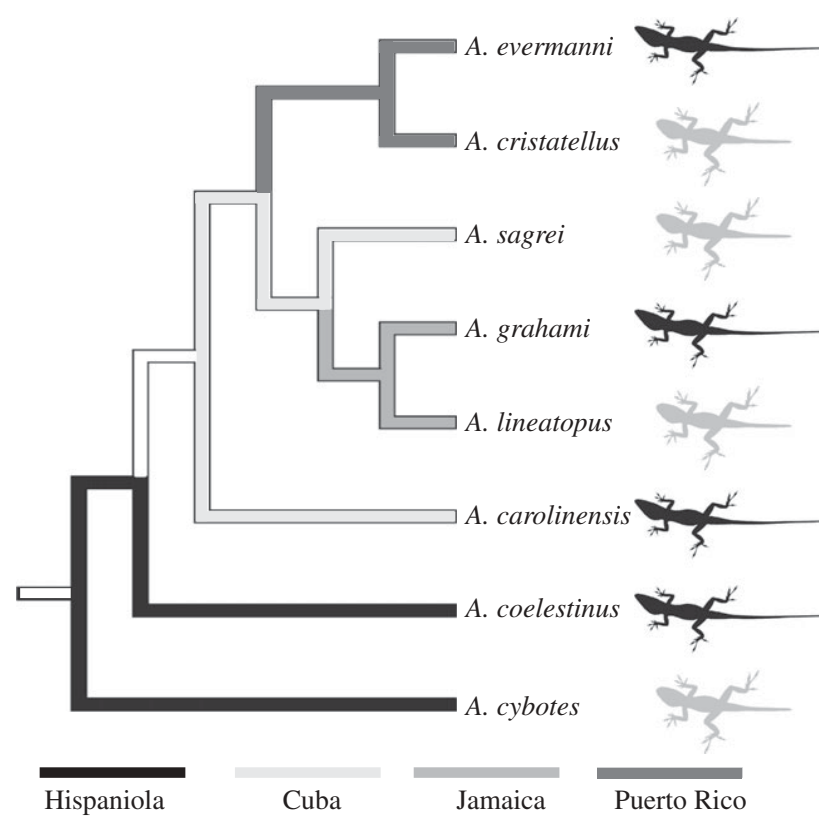

Figure 3. Phylogeny of eight anole species used in this study depicting independence of comparisons between island habitat specialists. Cartoons in the margin depict habitat specialist classification of each species (grey, trunk-ground; black, trunk-crown). Note that habitat specialists have evolved independently on each island.

the limb elements were obtained using a Nikon DN100 camera mounted on a Nikon SMZ1000 dissecting microscope. We obtained individual long bone measurements with IMAGEJ using a single linear measurement $[52,53]$.

\section{(c) Statistical analysis}

Log-transformed limb data for each species were best fit using a linear regression [54]. For each island pair, we tested for differences in slope and intercept between the two species with analysis of covariance (ANCOVA). To test for deviations from isometry (slope of the $\log -\log$ regression $=1$ ), we used a $t$-test for differences in slope for each species [55]. Embryonic and post-hatching data were treated independently.

To verify the results of this analysis using a second method, we also performed an ANCOVA using all posthatching data, testing whether species across islands differed in slope. Because no significant differences in slope were found (see below), we then performed a phylogenetic ANOVA on the mean of the residuals for each species obtained from a single linear regression through all data. Residuals indicate the extent to which each species's limb 
elements, relative to body size, are larger or smaller than expected based on the data from all the species in the study; these residuals can thus be used to determine whether the ecomorphs differ in relative limb length. A phylogenetic ANOVA [56] controls for the relatedness of the taxa $[57,58]$. To perform the phylogenetic ANOVA, we first obtained an unbiased estimate of the evolutionary variance-covariance matrix [59]. Using multivariate Brownian motion simulations on a phylogeny of the eight species (figure 3) [60], we then generated 999 simulated datasets. The probability value for this analysis is the proportion of the simulations in which the simulated $F$-statistic is greater than the empirical $F$-statistic. All statistical procedures were run using SYSTAT v. 10.2 (Systat Software Inc., San Jose, CA, USA) or C code written expressly for this study and available from one of the authors (L.J.R.) upon request.

\section{RESULTS}

\section{(a) Relative growth of post-hatching limbs}

Variation in relative hindlimb length in adults is associated solely with changes that occur before hatching. This is clearly illustrated by significant differences in intercept, represented by a transposition in the posthatching allometric regression (figure 4; table 1; electronic supplementary material, appendix S2). Both hindlimb elements examined (femur and tibia) exhibit the same pattern of post-hatching isometric growth. In no instance did we find significant differences in slope between species from the same island. Therefore, differences in relative hindlimb length cannot be attributed to differences in post-hatching allometric growth.

Forelimb elements exhibit different patterns of divergence on different islands. Significant differences in slope were never found between species from the same island. Only the forelimb elements from Cuban and Hispaniolan species have statistically distinguishable intercepts (figure 4; table 1; electronic supplementary material, appendix S2). Jamaican and Puerto Rican species vary neither in slope nor intercept, and the allometric trajectories vary only by ontogenetic scaling. Similar to the patterns shown by the hindlimbs, divergence of forelimb elements for Cuban and Hispaniolan species cannot be attributed to post-hatching allometric growth, but rather to a process that occurs prior to hatching.

Phylogenetic ANOVAs using species residuals support these conclusions (figure 5; electronic supplementary material, appendix S3). Trunk-ground anoles have relatively longer hindlimb elements than trunk-crown anoles, but the relative size of the forelimb elements does not differ.

\section{(b) Relative growth of embryonic limbs}

By stage 10, 'early digital web reduction' [45] (figure 1), the relative size of the long bones is well established. Significant differences in intercept occur between the Cuban species' forelimbs and hindlimbs, and among the hindlimbs of Jamaican species (figure 6; table 1). Forelimbs are indistinguishable between the two Jamaican species, just as they are after hatching. Significant positive allometry exists for many of the embryonic long bones in these species (electronic supplementary material, appendix S4). But despite the decreased rate of long bone growth after hatching, these results indicate that the differences between ecomorphs have already been determined by the earliest stage at which repeatable measurements are possible.

\section{DISCUSSION}

Do properties of development affect the rate or direction of morphological evolution, or does natural selection simply remould variation to match current ecological conditions? Phenotypic convergence provides us with the opportunity to test this long-standing question by comparing the effects of natural selection and developmental biases during morphological evolution. If development were, in fact, channelling evolution along particular paths, one would expect that lineages converging phenotypically would use the same developmental trajectories.

Our analyses of post-hatching growth trajectories for Anolis trunk-ground and trunk-crown habitat specialists show that adult limb length variation is consistently the result of changes that occur prior to hatching (figures 4 and 5): differences in limb length are apparent at hatching, and limb long bones elongate in parallel relative to body size in different species. Examination of prehatching embryonic growth shows that species-specific morphologies are the result of changes that occur very early in limb development, prior to formation of the cartilaginous anlagen (figure 6). These results therefore suggest roles for both natural selection and the generative mechanisms regulating limb length variation during the diversification of this genus.

Several evolutionary scenarios can explain the repeated recruitment of early limb morphogenesis programmes for the generation of interspecific variation in adult limb length. Vavilov [61] and Haldane [62] observed that closely related species tend to vary in similar directions, suggesting commonalities in their developmental-genetic architecture. Such common genetic architectures might predispose evolutionary changes to occur along similar lines, following what has been termed 'genetic lines of least resistance' [63]. Under this scenario, while different developmental trajectories are possible, development serves as a channelling force by making some outcomes more easily attained by selection than others. Within a theoretical context, developmental constraints must align with genetic constraints to have a lasting evolutionary impact [64]. Although certainly possible in theory, Anolis is a very old genus (estimated age is at least 40 million years [30]); finding conserved genetic architectures over such great periods of time might be considered surprising ([65-68] and references therein; but see [69] for evidence of conserved phenotypic integration over long evolutionary timescales in anoles).

Alternatively, it may well be that, owing to the developmental architecture of the limb, there are only a limited number of ways that variation in adult morphology can be accomplished developmentally; in other words, the only way to modify an anole's limb morphology might be through changes in the size of the cartilaginous anlagen [44]. This would represent a form of absolute or global constraint, whereby some possibilities cannot be attained owing to the constraints of limb development. However, limbs are complex structures, and processes active during later development and growth are known to contribute to limb length variation, both within species 


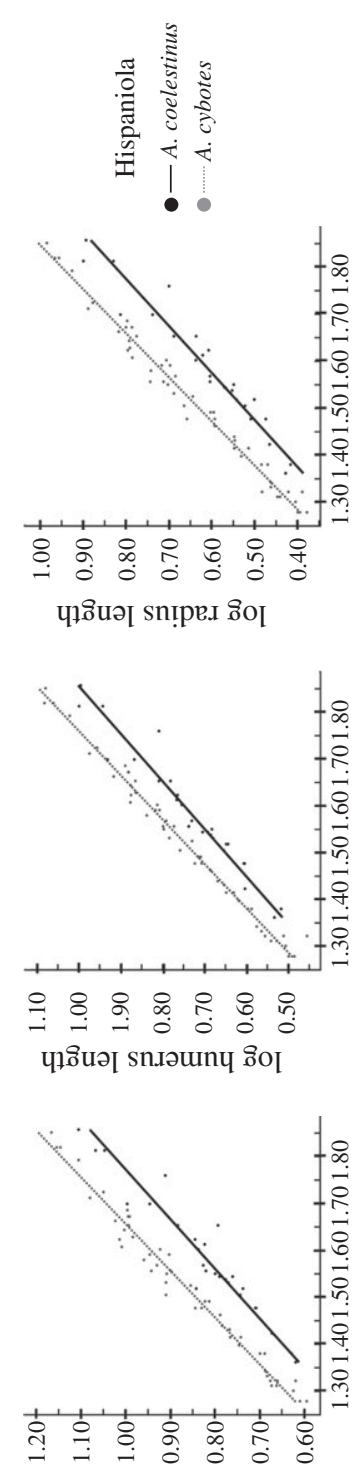

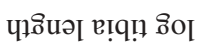

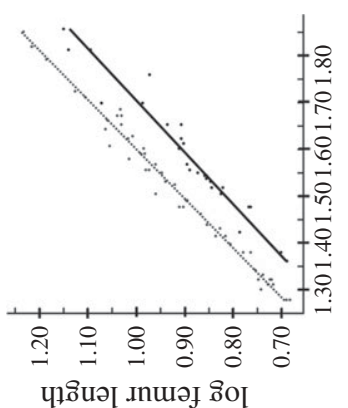

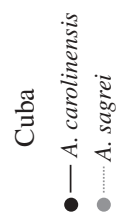

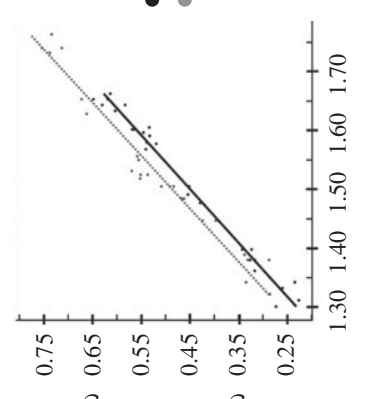

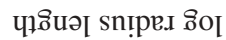

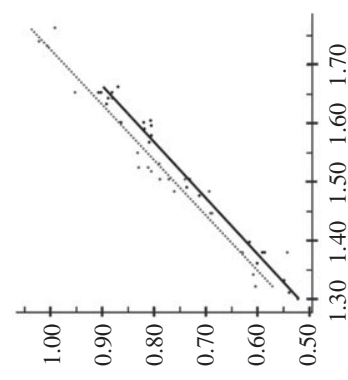

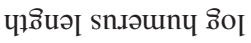

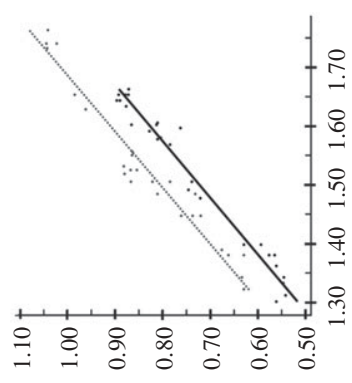

Чเภินว หฺ̣!ฺ ภิ०

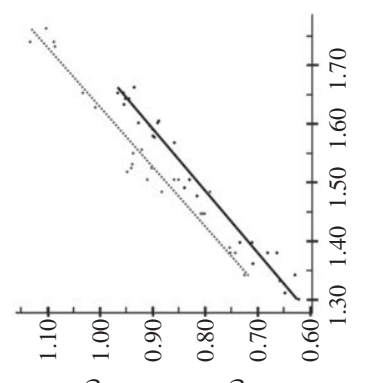

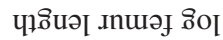
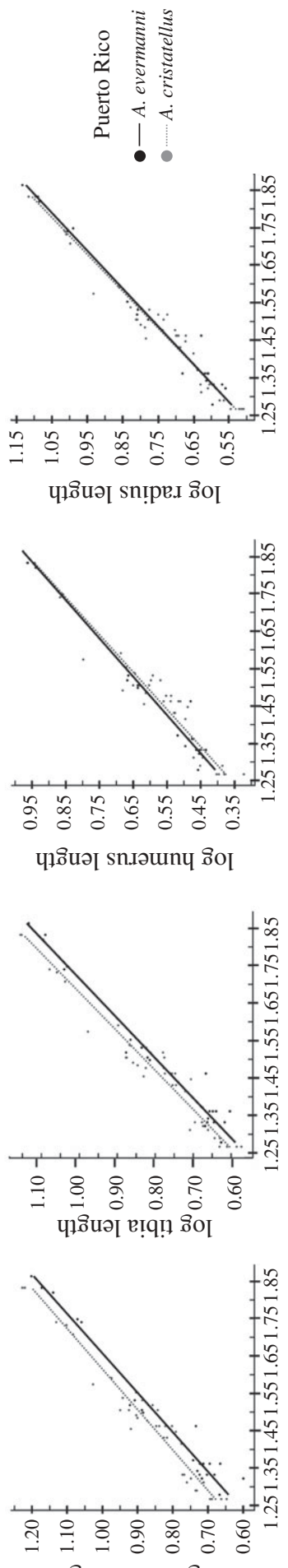
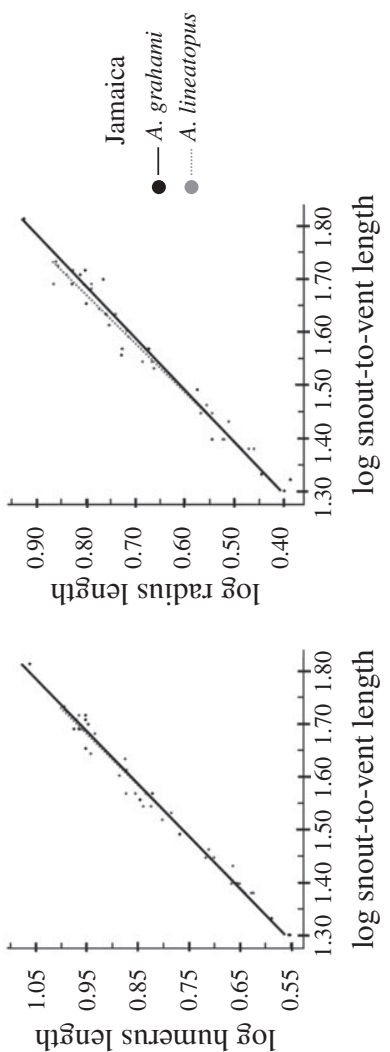

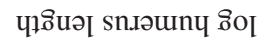

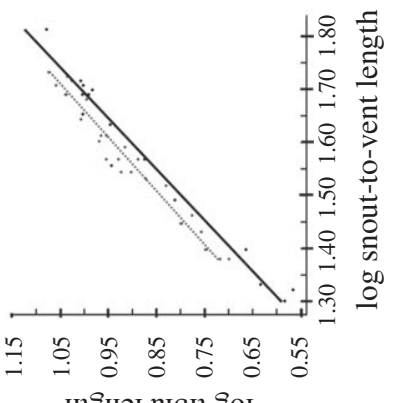

บเภินว ห!ด!ฺ ถิอเ

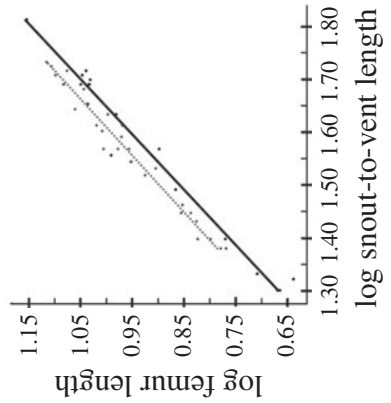


Table 1. Comparisons of relative limb growth between species from the same island. We found no significant differences in slope for any species pairs. Notice that post-hatching allometric trajectories for hindlimb elements show significant differences in intercept on all islands, while only Cuban and Hispaniolan forelimb elements show significant differences. Similar patterns were recovered in the embryonic analysis. Significant comparisons are highlighted in bold.

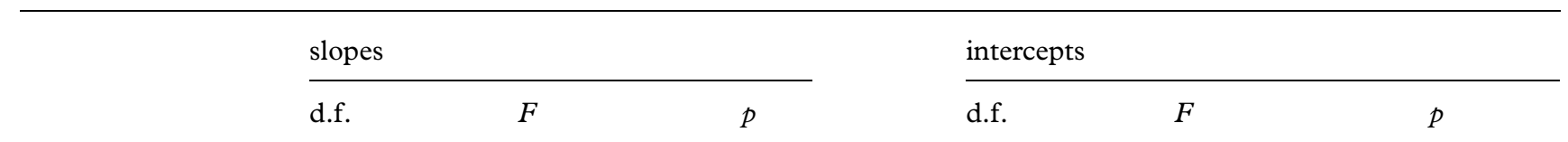

post-hatching allometry

Cuba

A. sagrei versus $A$. carolinensis

\begin{tabular}{|c|c|c|c|c|c|c|}
\hline femur & 1,42 & 1.257 & 0.269 & 1,43 & 72.278 & $p<0.0001$ \\
\hline tibia & 1,42 & 0.34 & 0.563 & 1,43 & 94.614 & $p<0.001$ \\
\hline humerus & 1,42 & 0.361 & 0.551 & 1,43 & 17.427 & $p<0.0001$ \\
\hline radius & 1,42 & 0.417 & 0.522 & 1,43 & 27.108 & $p<0.0001$ \\
\hline
\end{tabular}

Jamaica

$A$. lineatopus versus $A$. grahami

\begin{tabular}{|c|c|c|c|c|c|c|}
\hline femur & 1,38 & 0.029 & 0.866 & 1,39 & 26.346 & $p<0.001$ \\
\hline tibia & 1,38 & 0.145 & 0.705 & 1,39 & 19.807 & $p<0.001$ \\
\hline humerus & 1,38 & 0.371 & 0.546 & 1,39 & 0.177 & 0.677 \\
\hline radius & 1,38 & 1.685 & 0.202 & 1,39 & 0.449 & 0.507 \\
\hline
\end{tabular}

Hispaniola

$A$. cybotes versus $A$. coelestinus

\begin{tabular}{|c|c|c|c|c|c|c|}
\hline femur & 1,70 & 1.098 & 0.298 & 1,71 & 248.036 & $p<0.0001$ \\
\hline tibia & 1,70 & 1.213 & 0.275 & 1,71 & 203.093 & $p<0.0001$ \\
\hline humerus & 1,70 & 2.54 & 0.115 & 1,71 & 158.09 & $p<0.0001$ \\
\hline radius & 1,70 & 1.638 & 0.205 & 1,71 & 231.776 & $p<0.0001$ \\
\hline
\end{tabular}

Puerto Rico

A. cristatellus versus $A$. evermanni

\begin{tabular}{|c|c|c|c|c|c|c|}
\hline femur & 1,57 & 0.178 & 0.675 & 1,58 & 21.87 & $p<0.001$ \\
\hline tibia & 1,57 & 0.147 & 0.703 & 1,58 & 11.226 & $p<0.001$ \\
\hline humerus & 1,57 & 0.233 & 0.631 & 1,58 & 0.292 & 0.591 \\
\hline radius & 1,57 & 0.206 & 0.651 & 1,58 & 2.028 & 0.16 \\
\hline
\end{tabular}

embryonic limb allometry

Cuba

A. sagrei versus $A$. carolinensis

\begin{tabular}{|c|c|c|c|c|c|c|}
\hline femur & 1,34 & 0.087 & 0.77 & 1,35 & 31.137 & $p<0.001$ \\
\hline tibia & 1,34 & 1.937 & 0.173 & 1,35 & 39.659 & $p<0.001$ \\
\hline humerus & 1,34 & 0.006 & 0.937 & 1,35 & 16.99 & $p<0.001$ \\
\hline radius & 1,34 & 0.782 & 0.383 & 1,35 & 8.884 & $p<0.001$ \\
\hline
\end{tabular}

Jamaica

A. lineatopus versus $A$. grahami

\begin{tabular}{|c|c|c|c|c|c|c|}
\hline femur & 1,31 & 0.394 & 0.535 & 1,32 & 5.515 & 0.025 \\
\hline tibia & 1,31 & 0.003 & 0.956 & 1,32 & 5.694 & 0.023 \\
\hline humerus & 1,31 & 0.591 & 0.448 & 1,32 & 0.993 & 0.326 \\
\hline radius & 1,31 & 0.123 & 0.728 & 1,32 & 0.007 & 0.934 \\
\hline
\end{tabular}

(e.g. [34,35,37]) and among species (e.g. [41]; reviewed in [69]). In addition, forelimb and hindlimb elements appear to respond to selection independently on Jamaica (figures 3 and 4), and other lizard species exhibit nonisometric growth trajectories [70,71], which further indicates that no global constraints preclude allometric changes in limb dimensions.

A third possibility is that selection favouring differences in limb length between species in different habitats operates throughout their life histories. This would create strong functional and genetic correlations between early and late developmental stages [72]. If selection favours differences in limb length among juveniles, then it is possible that such differences might most easily be accomplished evolutionarily through changes in pre-hatching development, explaining why similar patterns recur repeatedly among species. Consistent selection throughout life would explain why there is no positive limb allometry in juvenile lizards; but because selection presumably does not act directly on limb length in developing embryos, this cannot explain why differences are repeatedly accomplished through early changes in limb morphogenesis time and time again.

At this time, it is not possible to distinguish between these competing evolutionary hypotheses. As mentioned above, deeply conserved developmental constraints may have channelled variation along certain dimensions, but the age and history of anoles make conserved genetic constraints seem unlikely. In addition, limb morphogenesis is highly variable in other vertebrate species, indicating that the overall developmental architecture of the limb is unlikely to channel the response to selection to particular developmental processes. Is it possible that the radiation of Anolis lizards used similar 'genetic lines of least 

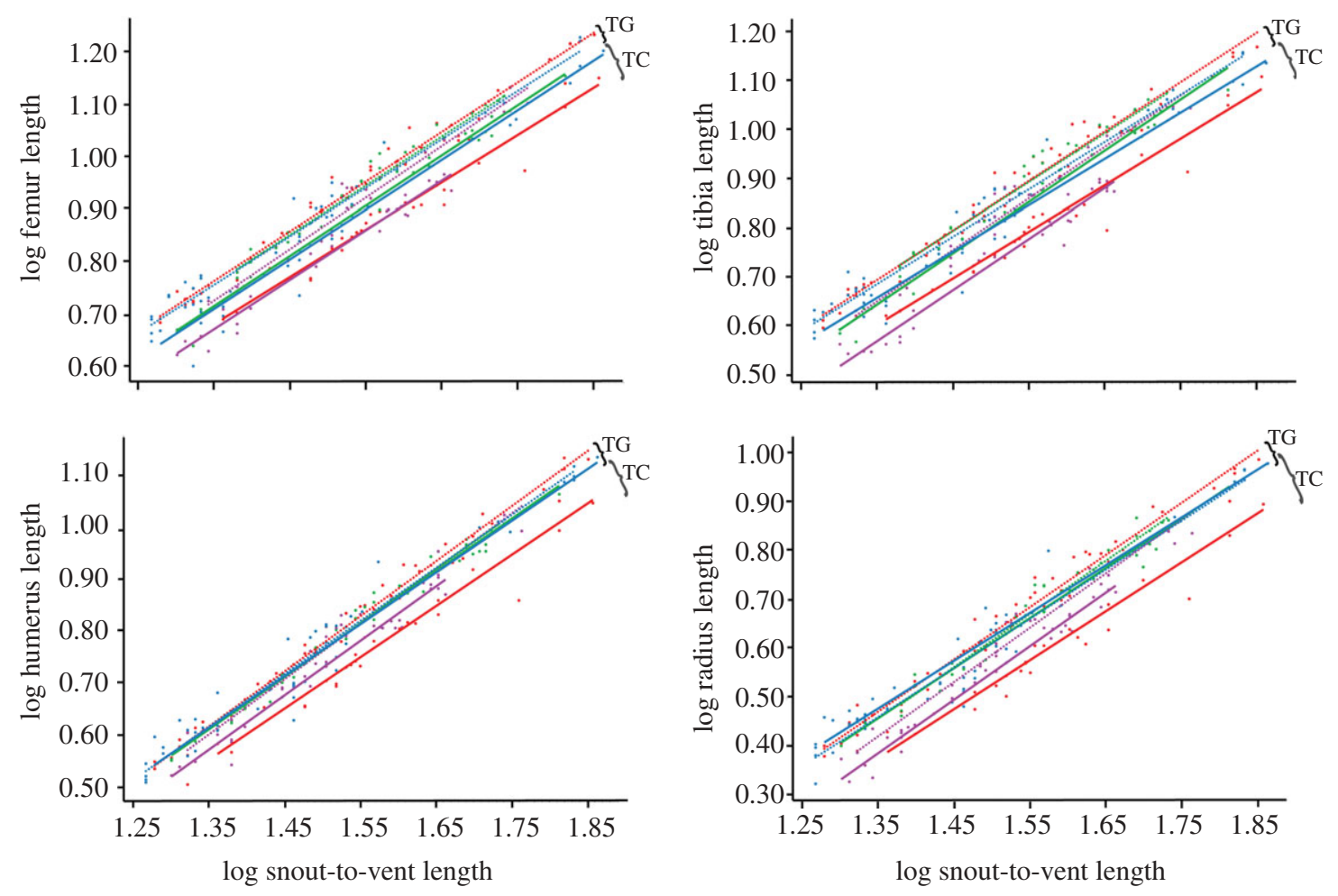

Figure 5. Summary of allometric plots of post-hatching growth series organized by island and habitat. Despite variation in the degree of divergence in limb proportions on each island, trunk-ground anoles consistently have relatively longer hindlimbs compared with the trunk-crown anole from the same island. Ecomorph: solid line, trunk-crown; dotted line, trunk-ground. Islands: red lines, Hispaniola; purple lines, Cuba; blue lines, Puerto Rico; green line, Jamaica.
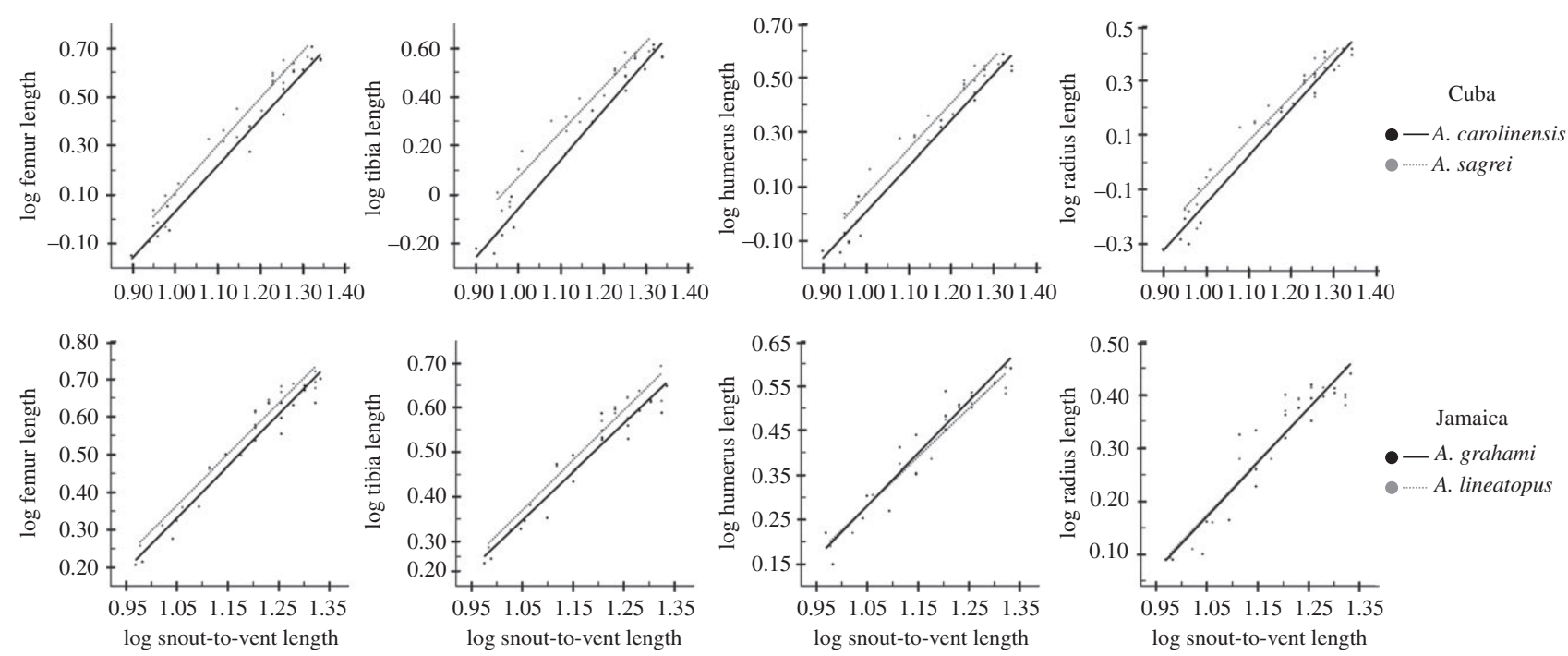

Figure 6. Plots of the relative growth of embryonic hindlimb elements highlighting the developmental origin of the ecomorphological variation early in development. Note the parallel allometric trajectories arising at the earliest stages of long bone development.

resistance' to rapidly diversify? Could the genetic architecture of early limb patterning actually channel the response to selection? addressing these questions will lead to a more thorough understanding of the relative roles of selection and constraint in shaping the radiation of Anolis lizards, but will require further data on the underlying genetics of limb development among anole species, a greater understanding of the molecular underpinnings of limb variation within species, and further data on the habitat preferences of hatchlings and juvenile lizards.
Have anoles diversified in limb length through convergence or in parallel? While the distinction between these terms is contentious $[8,23]$, a key factor often used to distinguish parallelism from convergence is whether the same developmental mechanisms underlie convergent phenotypes. In this light, parallelisms are a special case of convergence: parallelisms represent the interaction between selection and shared developmental constraints, while convergence is a more general phenomenon that can arise through multiple, unrelated evolutionary mechanisms (reviewed in [8]). Based on our results, we cannot 
rule out the possibility that anoles have evolved in parallel, by selection acting on a common set of developmental parameters controlling the size of the long bone anlagen. However, it is also possible that anoles have converged both morphologically and developmentally for reasons other than developmental constraint, as discussed above. The ultimate test of the parallel evolution hypothesis will be finding similarities in the genomic signature of natural selection to determine whether changes to the same loci have been independently selected on each island. Exploitation of the soon-to-be-published Anolis carolinensis genome, along with more detailed studies of natural history and development, should provide greater clarity regarding the relative importance of natural selection versus developmental constraint in guiding the evolutionary trajectory of Anolis.

Biologists are only just starting to bridge the divide between studies of natural selection and molecular genetics, providing a more detailed mechanistic understanding of the adaptive process [73]. But many of the best-studied examples of developmental evolution-where the specific genetic loci involved have been identified-have focused on discrete traits such as the presence or absence of specific characters (e.g. pelvic spines [19,74], wing spots [21] or vertebrate limbs [31]). Most studies of adaptation and divergence, however, focus on subtler, quantitative changes $[75,76]$. Thus, to connect studies of developmental evolution with the vast majority of studies of selection in nature, we need to shift our focus to quantitatively varying traits, the genetic basis of which is probably considerably more complicated than that in many of the model systems currently studied in evolutionary developmental biology.

Many people have helped with the collection and preparation of specimens examined in this article, most notably Michele Johnson, Paul Hime, Matt Edger, Alex Gamble and Kristin Sanger. Care and maintenance of the captive bred colonies would not have been nearly as successful without the assistance of Paul Hime, Jack Diani, Chip Deggendorf and Dan Piatchek, and other members of the Washington University in St Louis Animal Care and Use Committee. Jim Cheverud also aided in statistical analyses and interpretation. Hopi Hoekstra provided valuable comments on a previous version of this manuscript. We would also like to thank the governments of Jamaica, the Dominican Republic and Puerto Rico for permission to collect and export these specimens. This work was supported by a generous grant from the David and Lucile Packard Foundation, the National Science Foundation (award no. 0508696), Sigma xi, and the Department of Biology, Washington University in St Louis.

\section{REFERENCES}

1 Bateson, W. 1909 Mendel's principles of heredity. Cambridge, UK: Cambridge University Press.

2 Goldschmidt, R. 1940 The material basis of evolution. New Haven, CT: Yale University Press.

3 Huxley, J. 1942 Evolution: the modern synthesis. Cambridge, MA: MIT Press.

4 Arthur, W. 2004 Biased embryos and evolution. Cambridge, UK: Cambridge University Press.

5 Amundson, R. 2005 The changing role of the embryo in evolutionary thought. Cambridge, UK: Cambridge University Press.

6 Simpson, G. G. 1944 Tempo and mode in evolution. New York, NY: Columbia University Press.

7 Maynard-Smith, J. R., Burian, R., Kaufffman, S., Alberch, P., Campbell, J., Goodwin, B., Lande, R., Raup, D. \&
Wolpert, L. 1985 Developmental constraints and evolution. Q. Rev. Biol. 60, 265-287. (doi:10.1086/414425)

8 Losos, J. B. 2011 Convergence, adaptation, and constraint. Evolution 65, 1827-1840. (doi:10.1111/j.15585646.2011.01289.x)

9 Wake, D. B., Wake, M. H. \& Specht, C. D. 2011 Homoplasy: from detecting pattern to determining process and mechanism of evolution. Science 331, 1032-1035. (doi:10.1126/science.1188545)

10 Wake, D. B. 1991 Homoplasy: the result of natural selection, or evidence of design limitations? Am. Nat. 138, 543-567. (doi:10.1086/285234)

11 Gould, S. J. 2002 The structure of evolutionary theory. Cambridge, MA: Harvard University Press.

12 Schluter, D., Clifford, E. A., Nemethy, M. \& McKinnon, J. S. 2004 Parallel evolution and inheritance of quantitative traits. Am. Nat. 163, 809-822. (doi:10.1086/383621)

13 Whittall, J. B., Voelckel, C. \& Hodges, S. A. 2006 Convergence, constraint and the role of gene expression during adaptive radiation: floral anthocyanins in Aquilegia. Mol. Ecol. 15, 4645-4657. (doi:10.1111/j. 1365-294X.2006.03114.x)

14 Atallah, J., Liu, N. H., Dennis, P., Hon, A. \& Larsen, E. W. 2009 Developmental constraints and convergent evolution in Drosophila sex comb formation. Evol. Dev. 11, 205-218. (doi:10.1111/j.1525-142X.2009.00320.x)

15 Des Marais, D. L. \& Rausher, M. D. 2010 Parallel evolution at multiple levels in the origin of hummingbird pollinated flowers in Ipomoea. Evolution 64, 2044-2054.

16 Hamburger, V. 1980 Embryology and the modern synthesis in evolutionary theory. In The evolutionary synthesis (eds E. Mayr \& W. B. Provine), pp. 97-112. Cambridge, MA: Harvard University Press.

17 Gould, S. J. 1977 Ontogeny and phylogeny Cambridge, MA: Harvard University Press.

18 Duboule, D. \& Dolle, P. 1989 The structural and functional organization of the murine HOX gene family resembles that of Drosophila homeotic genes. EMBO $\mathcal{F}$. 8, 1497-1505.

19 Shapiro, M. D., Marks, M. E., Peichel, C. L., Blackman, B. K., Nereng, K. S., Jonsson, B., Schluter, D. \& Kingsley, D. M. 2004 Genetic and developmental basis of evolutionary pelvic reduction in threespine sticklebacks. Nature 428, 717-723. (doi:10.1038/nature02415)

20 Colosimo, P. F. et al. 2005 Widespread parallel evolution in sticklebacks by repeated fixation of ectodysplasin alleles. Science 307, 1928-1933. (doi:10.1126/science. 1107239)

21 Prud'homme, B., Gompel, N., Rokas, A., Kassner, V. A., Williams, T. M., Yeh, S., True, J. R. \& Carroll, S. B. 2006 Repeated morphological evolution through cis-regulatory changes in a pleiotropic gene. Nature 440, 1050-1053. (doi:10.1038/nature04597)

22 Derome, N., Duchesne, P. \& Bernatchez, L. 2006 Parallelism in gene transcription among sympatric lake whitefish (Coregonus clupeaformis Mitchill) ecotypes. Mol. Ecol. 15, 1239-1249. (doi:10.1111/j.1365-294X.2005.02968.x)

23 Arendt, J. \& Reznick, D. 2008 Convergence and parallelism reconsidered: what have we learned about the genetics of adaptation? Trends Ecol. Evol. 23, 26-32. (doi:10.1016/j.tree.2007.09.011)

24 Manceau, M., Domingues, V. S., Linnen, C. R., Rosenblum, E. B. \& Hoekstra, H. E. 2010 Convergence in pigmentation at multiple levels: mutations, genes and function. Phil. Trans. R. Soc. B 1552, 2439-2450. (doi:10.1098/rstb.2010.0104)

25 Elmer, K. R. \& Meyer, A. 2011 Adaptation in the age of ecological genomics: insights from parallelism and convergence. Trends Ecol. Evol. 26, 298-306. (doi:10.1016/ j.tree.2011.02.008) 
26 Cooper, W. J. \& Albertson, R. C. 2008 Quantification and variation in experimental studies of morphogenesis. Dev. Biol. 321, 295-302. (doi:10.1016/j.ydbio.2008.06.025)

27 Klingenberg, C. P. 2010 Evolution and development of shape: integrating quantitative approaches. Nat. Rev. Genet. 11, 623-635.

28 Grant, P. R. 1999 Ecology and evolution of Darwin's finches. Princeton, NJ: Princeton University Press.

29 Schluter, D. 2000 The ecology of adaptive radiation. Oxford, UK: Oxford University Press.

30 Losos, J. B. 2009 Lizards in an evolutionary tree: ecology and adaptive radiation of anoles. Berkeley, CA: University of California Press.

31 Cohn, M. J. \& Tickle, C. 1999 Developmental basis of limblessness and axial patterning in snakes. Nature 399, 474-479. (doi:10.1038/20944)

32 Abzhanov, A., Kuo, W. P., Hartmann, C., Grant, B. R., Grant, P. R. \& Tabin, C. J. 2006 The calmodulin pathway and evolution of elongated beak morphology in Darwin's finches. Nature 442, 563-567. (doi:10.1038/nature04843)

33 Abzhanov, A., Protas, M., Grant, B. R., Grant, P. R. \& Tabin, C. J. $2004 \mathrm{Bmp} 4$ and morphological variation of beaks in Darwin's finches. Science 305, 1462-1465. (doi:10.1126/science.1098095)

34 Farnum, C. E., Tinsley, M. \& Hermanson, J. W. 2008 Postnatal bone elongation of the manus versus pes: analysis of the chondrocytic differentiation cascade in Mus musculus and Eptesicus fuscus. Cells Tissues Organs 187, 48-58. (doi:10.1159/000109963)

35 Farnum, C. E., Tinsley, M. \& Hermanson, W. 2008 Forelimb versus hindlimb skeletal development in the big brown bat, Eptesicus fuscus: functional divergence is reflected in chondrocytic performance in autopodial growth plates. Cells Tissues Organs 187, 35-47. (doi:10. 1159/000109962)

36 Adams, D. C. \& Nistri, A. 2010 Ontogenetic convergence and evolution of foot morphology in European cave salamanders (Family: Plethodontidae). BMC Evol. Biol. 10, 216. (doi:10.1186/1471-2148-10-216)

37 Sanger, T. J., Norgard, E. Z., Pletscher, L. S., Bevilacqua, M., Brooks, V. R., Sandell, L. B. \& Cheverud, J. M. 2010 Developmental and genetic origins of murine long bone length variation. F. Exp. Biol. 314B, 1-16.

38 Alberch, P., Gould, S. J., Oster, G. F. \& Wake, D. B. 1979 Size and shape in ontogeny and phylogeny. Paleobiology 5, 296-317.

39 Klingenberg, C. P. 1998 Heterochrony and allometry: the analysis of evolutionary change in ontogeny. Biol. Rev. 73, 79-123. (doi:10.1017/S000632319800512X)

40 Sears, K. E., Behringer, R. R., Rasweiler, J. J. \& Niswander, L. A. 2006 The development of bat flight: morphologic and molecular evolution of bat forelimb digits. Proc. Natl Acad. Sci. USA 103, 6581-6586. (doi:10.1073/pnas.0509716103)

41 Rolian, C. 2008 Developmental basis of limb length in rodents: evidence for multiple divisions of labor in mechanisms of endochondral bone growth. Evol. Dev. 10, 15-28. (doi:10.1111/j.1525-142X.2008.00211.x)

42 Ray, R. \& Capecchi, M. R. 2008 An examination of the chiropteran HoxD locus from an evolutionary perspective. Evol. Dev. 10, 657-670. (doi:10.1111/j.1525-142X.2008. 00279.x)

43 Hockman, D., Mason, M. K., Jacobs, D. S. \& Illing, N. 2009 The role of early development in mammalian limb diversification: a descriptive comparison of early limb development between the natal long-fingered bat (Miniopterus natalensis) and the mouse (Mus musculus). Dev. Dynam. 238, 965-979. (doi:10.1002/dvdy.21896)

44 Hall, B. K. 2003 Unlocking the black box between genotype and phenotype: cell condensations as morphogenetic (modular) units. Biol. Philos. 18, 219-247. (doi:10.1023/ A:1023984018531)

45 Sanger, T. J., Losos, J. B. \& Gibson-Brown, J. J. 2008 A developmental staging series for the lizard genus Anolis: a new system for the integration of evolution, development, and ecology. F. Morph. 269, 129-137. (doi:10.1002/jmor.10563)

46 Sanger, T. J., Hime, P. M., Johnson, M. A. \& Diani, J. 2008 Protocols for husbandry and embryo collection of Anolis lizards. Herpetol. Rev. 39, 58-63.

47 Beuttell, K. \& Losos, J. B. 1999 Ecological morphology of Caribbean anoles. Herpetol. Monogr. 13, 1-28. (doi:10.2307/1467059)

48 Calsbeek, R. \& Smith, T. B. 2007 Probing the adaptive landscape using experimental islands: density-dependent natural selection on lizard body size. Evolution 61-65, 1052-1061. (doi:10.1111/j.1558-5646.2007.00093.x)

49 Hanken, J. \& Wassersug, R. 1981 The visible skeleton: a new double-stain technique reveals the nature of the 'hard' tissues. Funct. Photogr. 16, 22-26.

50 Taylor, W. R. \& Dyke, G. C. V. 1985 Revised procedures for staining and clearing small fishes and other vertebrates for bone and cartilage study. Cybium 9, 107-119.

51 Walker, M. B. \& Kimmel, C. B. 2007 A two-color acid-free cartilage and bone stain for zebrafish larvae. Biotechnic. Histochem. 82, 23-28. (doi:10.1080/10520290701333558)

52 Rasband, W. S. 1997 Imagef. Bethesda, MD: US National Institutes of Health.

53 Abramoff, M. D., Magelhaes, P. J. \& Ram, S. J. 2004 Image processing with ImageJ. Biophotonics Int. 11, 36-42.

54 Huxley, J. S. 1932 Problems of relative growth. London, UK: Methuen.

55 Sokal, R. R. \& Rohlf, F. J. 1995 Biometry, 3rd edn. New York, NY: Freeman and Company.

56 Garland Jr, T., Dickerman, A. W., Janis, C. M. \& Jones, J. A. 1993 Phylogenetic analysis of covariance by computer simulation. Syst. Biol. 42, 265-292.

57 Felsenstein, J. 1985 Phylogenies and the comparative method. Am. Nat. 125, 1-15. (doi:10.1086/284325)

58 Harvey, P. H. \& Pagel, M. D. 1991 The comparative method in evolutionary biology. Oxford, UK: Oxford University Press.

59 Revell, L. J. \& Harmon, L. J. 2008 Testing quantitative genetic hypotheses about the evolutionary rate matrix for continuous characters. Evol. Ecol. Res. 10, 311-321.

60 Nicholson, K. E., Glor, R. E., Kolbe, J. J., Larson, A., Hedges, S. B. \& Losos, J. B. 2005 Mainland colonization by island lizards. F. Biogeogr. 32, 929-938. (doi:10.1111/ j.1365-2699.2004.01222.x)

61 Vavilov, N. 1922 The law of homologous series in variation. F. Genet. 12, 67-87. (doi:10.1007/BF02983073)

62 Haldane, J. B. S. 1932 The causes of evolution. London, UK: Longman.

63 Schluter, D. 1996 Adaptive radiation along genetic lines of least resistance. Evolution 50, 1766-1796. (doi:10. 2307/2410734)

64 Cheverud, J. M. 1984 Quantitative genetics and developmental constraints on evolution by selection. F. Theor. Biol. 110, 155-171. (doi:10.1016/S0022-5193(84)80050-8)

65 Turelli, M. 1998 Phenotypic evolution, constant covariances, and the maintenance of additive evolution. Evolution 42, 1342-1347. (doi:10.2307/2409017)

66 Agrawal, A. F., Brodie, E. D. \& Reiseberg, L. H. 2001 Possible consequences of genes of major effect: transient changes in the G-matrix. Genetica 112-113, 33-43. (doi:10.1023/A:1013370423638)

67 Steppan, S. J., Phillips, P. C. \& Houle, D. 2002 Comparative quantitative genetics: evolution of the G matrix. Trends. Ecol. Evol. 17, 320-327. (doi:10.1016/ S0169-5347(02)02505-3) 
68 Arnold, S. J., Burger, R., Hohenlohe, P. A., Ajie, B. C. \& Jones, A. G. 2008 Understanding the evolution and stability of the G-matrix. Evolution 62, 2451-2461. (doi:10. $1111 / j .1558-5646.2008 .00472 . x)$

69 Kolbe, J. J., Revell, L. J., Szekely, B., Brodie, E. D. \& Losos III, J. B. In press. Convergent evolution of phenotypic integration and its alignment with morphological diversification in Caribbean Anolis ecomorphs. Evolution. (doi:10.1111/j.1558-5646.2011. 01416.x)

70 Pounds, J. A., Jackson, J. F. \& Shively, S. H. 1982 Allometric growth of the hind limbs of some terrestrial Iguanid lizards. Am. Midl. Nat. 110, 201-207. (doi:10. 2307/2425226)

71 Powell, G. L. \& Russell, A. P. 1992 Locomotor correlates of ecomorph designation in Anolis: an examination of three sympatric species from Jamaica. Can. F. Zool. 70, 725-739. (doi:10.1139/z92-107)
72 Riedl, R. 1978 Order in living organisms: a systems analysis of evolution. New York, NY: Wiley.

73 Linnen, C. R. \& Hoekstra, H. E. 2009 Measuring natural selection on genotypes and phenotypes. Cold Spring Harbor Symp. Quant. Biol. 74, 155-168. (doi:10.1101/ sqb.2009.74.045)

74 Shapiro, M. D., Bell, M. A. \& Kingsley, D. M. 2006 Parallel genetic origins of pelvic reduction in vertebrates. Proc. Natl Acad. Sci. USA 103, $13753-13$ 758. (doi:10. 1073/pnas.0604706103)

75 Kingsolver, J. G., Hoekstra, H. E., Hoekstra, J. M., Berrigan, D., Vignieri, S. N., Hill, C. E., Hoang, A., Gibert, P. \& Beerli, P. 2001 The strength of phenotypic selection in natural populations. Am. Nat. 157, 245-261. (doi:10.1086/319193)

76 Kingsolver, J. G. \& Pfennig, D. W. 2007 Patterns and power of phenotypic selection in nature. Bioscience 57, 561-572. (doi:10.1641/B570706) 